\title{
MPVerde - Modelo de Referência para Aplicação de Processos Verdes em Organizações de Software
}

\author{
Liliane Frez, Marcello Thiry, Alessandra Zoucas
}

Mestrado em Computação Aplicada - Universidade do Vale do Itajaí (UNIVALI)

88.302-202 - Itajaí - SC - Brasil

lili.frez@gmail.com, \{thiry, azoucas\}@univali.br

\begin{abstract}
This paper presents a reference model to support the implementation of green practices and processes in software development organizations. The proposed model is structured into capability and maturity levels, having been developed based on the concepts and practices of green IT. Current environmental concern brings a market differential for these organizations and can provide an organizational environment that fosters individual growth of its professionals. As an initial evaluation of the model, it is also presented the results of three model assessments in software development organizations.
\end{abstract}

Resumo. Este artigo apresenta um modelo de referência para apoiar a implementação de processos e práticas verdes em organizações de desenvolvimento de software. O modelo proposto é estruturado em níveis de capacidade e maturidade, tendo sido desenvolvido com base em conceitos $e$ práticas da TI verde. A preocupação com o meio ambiente traz um diferencial de mercado importante para estas organizações e pode proporcionar um ambiente organizacional que estimula o crescimento individual dos seus profissionais. Este trabalho apresenta ainda o resultado de avaliações do modelo em três organizações de desenvolvimento de software.

\section{Introdução}

A sustentabilidade ambiental é o tema principal do século XXI, visto que os impactos ambientais resultantes das ações do homem se agravam e os esforços para inibi-los ou diminuí-los precisam ser exigidos e priorizados (IPEA, 2010). Para acompanhar o rápido crescimento das indústrias, criou-se o conceito do desenvolvimento sustentável, onde o crescimento econômico deve acontecer aliado às necessidades sociais e ambientais (LAVILLE, 2009). Viabilizando, dessa forma, o desenvolvimento de ações socioeconômicas, ecoeficientes e socioambientais.

A indústria da Tecnologia da Informação (TI) também contribui para a ocorrência de problemas ambientais, que estão relacionados, principalmente, ao consumo excessivo de energia elétrica, a emissão de dióxido de carbono, que já alcança cerca de dois por cento das emissões mundiais, e a falta de tratamento dos lixos eletrônicos (MURUGESAN, 2008). A TI verde surge, portanto, como um assunto centralizador desta discussão, trazendo para o mercado de TI a importância do 
desenvolvimento sustentável e a necessidade do crescimento focado na preservação do meio ambiente.

Quando se trata especificamente de organizações de desenvolvimento de software, as questões ambientais são as mesmas, principalmente, devido aos recursos tecnológicos utilizados e a infraestrutura requerida (PEREIRA, 2010). Um fator agravante é a constante necessidade de aquisições de hardwares, seja por defeitos ou novas tecnologias, gerando lixos eletrônicos que podem estar sendo negligenciados.

Neste sentido, esta pesquisa observou que são necessárias mudanças organizacionais para que uma organização de software consiga implementar práticas de modo a contribuir para a melhoria e diminuição desses problemas ambientais.

Modelos de referência podem ser utilizados para diversas finalidades em que se propõe representar uma simplificação ou abstração da realidade (BOOCH, 2006). Com foco em sustentabilidade ambiental, é possível e, faz-se necessário (TACHIZAWA; POZO, 2010), o desenvolvimento de um modelo que apresente práticas e processos que apoiam a implantação deste conceito ambiental nas organizações de software. Por este motivo, a pesquisa propõe o desenvolvimento de um modelo de referência que descreve processos verdes a serem implementados visando à inserção da gestão ambiental em seus processos organizacionais. Com isto, as organizações de software serão guiadas a utilização de práticas que visam soluções ambientais.

O modelo proposto, denominado MPVerde, estimula a competitividade no mercado de software através da imagem sustentável, permitindo que estas organizações sejam qualificadas e avaliadas conforme um padrão de qualidade ambiental. A pesquisa ainda conclui que a implementação destas práticas ambientais pode estimular o desenvolvimento de um ambiente de trabalho propício à melhoria da qualidade dos produtos entregues.

\section{O Modelo de Referência Proposto}

O MPVerde apoia organizações de software no esforço para alcançar melhorias em processos visando à qualidade ambiental, mediante a concepção da gestão ambiental. $\mathrm{O}$ modelo de referência proposto tem como principal objetivo servir de instrumento para aplicação do desenvolvimento sustentável e foi baseado em pesquisas realizadas no campo da TI verde. O modelo também foi desenvolvido a partir da análise da norma ISO 14001 (ABNT, 2004), que define os requisitos necessários à concepção do sistema de gestão ambiental.

Para a concepção do MPVerde foi utilizado um framework como apoio na definição da estrutura do modelo o que viabilizou a utilização de padrões conhecidos nacional e internacionalmente, além de permitir a reutilização de componentes de diferentes métodos já existentes. O framework PRO2PI-MFMOD (ZOUCAS, 2010) foi avaliado e testado em pesquisas anteriores (SALVIANO et. al, 2009) e, por isso, foi selecionado para apoiar nesta pesquisa. 
No desenvolvimento do modelo, algumas atividades e técnicas foram realizadas baseadas nas definições do framework. As atividades executadas foram: 1 Levantamento de necessidades ambientais na TI e definição do público-alvo; 2 Revisão da literatura; 3 - Definição do padrão de documentação do processo, baseado na ISO/IEC 15504 e MPS.BR; 4 - Análise detalhada dos modelos selecionados; 5 Realização de reuniões com especialistas da ISO/IEC 15504 e MPS.BR para garantir a compatibilidade entre os modelos; 6 - Revisão da estratégia de desenvolvimento; 7 - A versão preliminar do modelo é analisada em formato de entrevista em três organizações de software. Estas atividades foram desenvolvidas a partir das "Práticas sequenciais" descritas no framework. As técnicas empregadas no MPVerde foram: Tradução de áreas de processo de um modelo existente; Aplicação de questionário; Revisão da literatura; Análise de trabalhos correlatos e Revisão pelos pares.

A instanciação do framework permitiu o desenvolvimento de um modelo de referência baseado em definições e conceitos de modelos reconhecidos e consistentes na Engenharia de Software. Com isso, espera-se uma aceitação maior do MPVerde nas organizações que já possuem algum nível de maturidade em modelos de qualidade de software.

\subsection{Definição do público-alvo}

Em estudos voltados para a TI Verde, observou-se que a tecnologia da informação contribui com problemas ambientais relacionados ao consumo inadequado de energia elétrica e a emissão de $\mathrm{CO}_{2}$. Em aspectos diretamente relacionados aos hardwares são discutidos os problemas envolvidos na exploração dos recursos naturais para fabricação dos equipamentos e o lixo eletrônico (MURUGESAN, 2008).

Em relação aos softwares também são encontradas pesquisas que discutem as problemáticas ambientais envolvidas. No ciclo de vida dos softwares podem ser analisadas questões relacionadas ao consumo de energia gasto durante a execução dos programas ou para manter a infraestrutura da fábrica de software (computadores, servidores, etc.), o uso de papéis nas fases de levantamento de requisitos ou de implantação do sistema para, por exemplo, a impressão de manuais (JOHANN et al., 2011), a grande demanda por aquisição de novos equipamentos ou componentes eletrônicos com maior desempenho ou ainda a troca de hardwares que se tornam obsoletos à medida que os softwares evoluem, dentre outros fatores (SAHIN et al., 2012).

Nesta análise é possível identificar, portanto, que para manter ou desenvolver softwares é necessário ter uma estrutura e desempenhar atividades que podem ter impacto sobre o meio ambiente. Dessa forma, verifica-se que a Engenharia de Software também deve envolver questões ambientais e buscar junto às organizações de software as melhores soluções para os problemas detectados. Baseado em aspectos sustentáveis e nos impactos ambientais relacionados à tecnologia da informação e identificados em organizações de softwares, esta pesquisa propõe a inserção de conceitos e práticas ambientais na Engenharia de Software. 
Engenharia de Software é "a aplicação de um processo sistemático, disciplinado e quantificado ao desenvolvimento, operação e manutenção de software" (IEEE, 1990). Dentro das definições da TI Verde, a Engenharia de Software deve aprimorar este conceito atendendo a objetivos ambientais tais como o consumo direto e indireto de recursos naturais e da energia elétrica, bem como as consequências encontradas durante o ciclo de vida do software, visando à monitoração, medição, avaliação e otimização contínua desses fatores (JOHANN et al., 2011).

O ciclo de vida de um software é composto basicamente pelas fases de desenvolvimento, implantação, utilização e desativação (ABNT, 2009). Cada uma dessas fases pode ser avaliada em relação a fatores de influência sobre o meio ambiente e a identificação desses fatores permite analisar a necessidade do desenvolvimento de um modelo de referência com processos e práticas que devem apoiar as organizações de software que buscam o desempenho ambiental em suas atividades.

\subsection{Estrutura do modelo}

O modelo tem como propósito abranger as atividades percebidas em organizações de software e propõe o desenvolvimento de softwares de forma favorável ao meio ambiente, promovendo a eficiência dos fatores ambientais relativos ao respectivo processo. A simples aplicação de ações pontuais e isoladas não garante $\mathrm{o}$ desenvolvimento sustentável. Para que este crescimento ocorra de forma contínua e evolutiva, algumas mudanças no processo organizacional são necessárias. Por este motivo, o modelo MPVerde apresenta a definição de novos processos voltados para a solução dos problemas ambientais relacionados a organização.

A garantia do sucesso da implantação deste modelo depende do comprometimento de diversos níveis e funções e, especialmente, da alta administração da empresa (ABNT, 2004). Por isto, o modelo implementa processos que dependem da execução de diversas áreas organizacionais, não somente de uma área específica. Análogo à ISO/IEC 14001 (ABNT, 2004), o modelo apresenta um aspecto de influência em diversas áreas organizacionais (ver Figura 1).

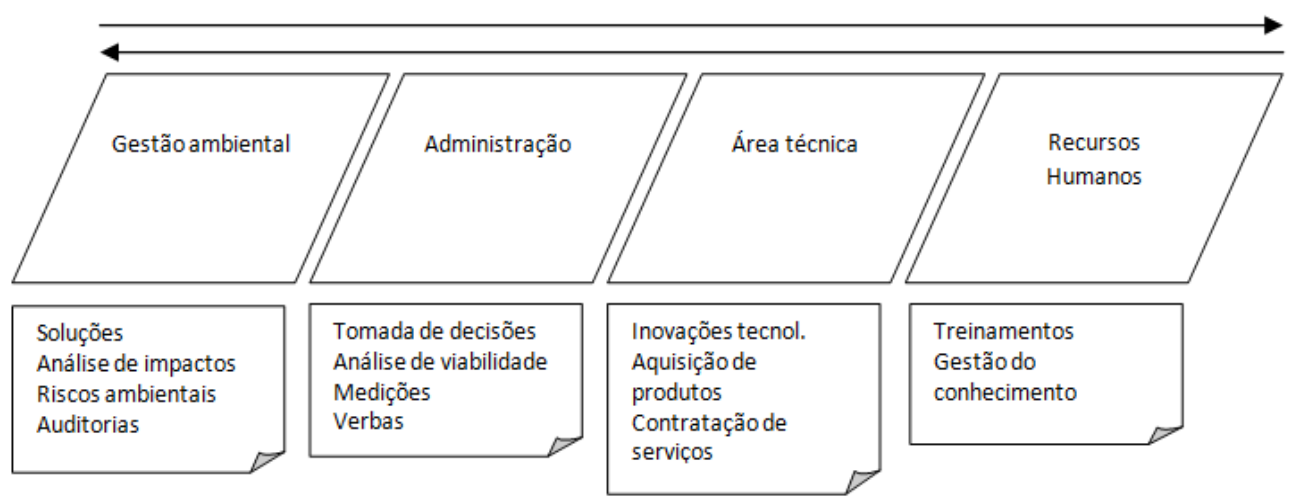

Figura 1. Principais áreas de negócio influenciadas pelo modelo 
A gestão ambiental é inserida neste cenário como uma nova área de negócio, indispensável para a implementação do modelo. Dela surgem soluções para problemas ambientais, denominadas soluções verdes. Estas soluções podem ser identificadas por meio da análise de impacto e riscos ambientais. Esta definição sugere que a organização que almeja a utilização do modelo, deva iniciar seus esforços com a concepção desta nova área de negócio. Além disso, outros setores são envolvidos nestas mudanças, como a Administração, responsável pelas decisões, medições, viabilidade e repasse de verbas. A Área técnica, que deve ser um suporte para as demais áreas, deve ser, principalmente, responsável pelas inovações tecnológicas, aquisição de novos produtos e serviços. E, por fim, a área de Recursos Humanos responsável por gerir o repasse das experiências e do conhecimento adquirido com as soluções e estudos ambientais. Estas formam as principais áreas de negócios envolvidas nas mudanças organizacionais propostas pelo MPVerde.

Os objetivos deste modelo são:

1. Agregar valor sustentável aos processos organizacionais;

2. Viabilizar mudanças organizacionais, através da gestão ambiental e suas principais influências nos processos organizacionais;

3. Evidenciar os impactos ambientais e as soluções tomadas para contingenciálos ou mitigá-los;

4. Promover a cultura organizacional sustentável, através da conscientização e capacitação das pessoas;

5. Ser uma ferramenta de avaliação e comparação entre as empresas.

Estes objetivos devem estar sempre acordados com os objetivos organizacionais. $\mathrm{Na}$ definição, um modelo de referência define processos que permitem atender aos objetivos organizacionais correntes e planejados (ABNT, 2008). Organizações que adotarem o MPVerde tem como objetivo de negócio o atendimento das necessidades ambientais em seus processos organizacionais e, portanto, estão conscientes da sua responsabilidade socioambiental.

O modelo está divido em três níveis de maturidade, onde o nível V1 é denominado Sustentabilidade Ambiental Gerenciada e presa pela implementação dos processos chamados de básicos. O nível V2 é denominado Sustentabilidade Ambiental Institucionalizada e tem como principal objetivo a integração dos processos através da realização de auditorias. O nível V3 é denominado Sustentabilidade Ambiental Contínua, pois pretender tornar a gestão ambiental um cenário contínuo na organização através das medições, coleta de indicadores e do repasse do conhecimento para todos os níveis hierárquicos da organização.

O nível V1 busca assegurar uma gestão organizada das iniciativas ambientais realizadas na organização. Estas iniciativas são identificadas como soluções verdes e são tratadas no primeiro processo do nível. Visando assegurar a gestão ambiental de soluções específicas para o centro de processamento de dados e para os lixos eletrônicos, os processos 2 e 3 do nível são responsáveis por estes assuntos. Para 
auxiliar na identificação destas soluções verdes, é definido o processo de análise de riscos e impactos ambientais.

O nível V2 visa garantir que os processos ambientais sejam incorporados aos demais processos organizacionais. Neste nível o processo de auditoria é estabelecido para assegurar que as soluções verdes estejam sendo executadas de forma a atender os objetivos ambientais da organização. Com foco no atendimento de requisitos ambientais relativos ao ciclo de vida do software, são definidos dois processos estabelecendo o atendimento das práticas ambientais voltadas para as fases de desenvolvimento, implantação e desativação do software. Ainda neste nível do modelo também é definido o processo de aquisição de produtos e contratação de fornecedores baseados em critérios ambientais.

O nível V3 permite analisar e medir os benefícios ganhos com a aplicação das soluções verdes através da medição e garante a gestão e a disseminação do conhecimento adquirido com a implantação das soluções.

\begin{tabular}{|c|c|c|c|c|}
\hline Processo & $\begin{array}{c}\text { Nível de } \\
\text { Maturidade }\end{array}$ & \begin{tabular}{|c|} 
Nivel de \\
Capacidade 1 \\
\end{tabular} & \begin{tabular}{|c|} 
Nível de \\
Capacidade 2 \\
\end{tabular} & $\begin{array}{c}\text { Nivel de } \\
\text { Capacidade } 3\end{array}$ \\
\hline GSV - Gerência da Solução Verde & V1 & \multirow{4}{*}{1} & \multirow{8}{*}{2} & \\
\hline GPD - Gerência do Centro de Processamento de Dados & V1 & & & \\
\hline GLE - Gerência do Lixo Eletrônico & V1 & & & \\
\hline GRA - Gerência de Riscos Ambientais & V1 & & & \\
\hline AQV - Aquisição Verde & $\mathrm{V} 2$ & & & \\
\hline AMS - Avaliação e Melhoria da Solução Verde & $\mathrm{V} 2$ & & & \\
\hline DVS - Desenvolvimento Verde de Software & $\mathrm{V} 2$ & & & \\
\hline IVS - Implantação e Desativação Verde de Software & V2 & & & \\
\hline MES - Medição da Solução Verde & V3 & & & \multirow{3}{*}{3} \\
\hline TOS - Treinamento para Soluçôes Verdes & V3 & & & \\
\hline GCA - Gerência do Conhecimento Ambiental & V3 & & & \\
\hline
\end{tabular}

Figura 2. Processos do modelo

A principal diferença entre o MPVerde e os demais modelos, é o fato de que o modelo propõem o atendimento das questões ambientais através da aplicação e gestão das soluções verdes. Ou seja, enquanto que no MPS.BR (SOFTEX, 2011), CMMI (SEI, 2010) e ISO 15504 (ABNT, 2008) a questão principal é a melhoria do software, para o MPVerde a questão principal é viabilizar a qualidade ambiental.

\subsection{Processo "Desenvolvimento Verde de Software"}

No nível 2 de maturidade do modelo são definidos os processos específicos da área da engenharia de software. Neste artigo é descrito o processo "DVS - Desenvolvimento Verde de Software" para demonstrar a forma de documentação do modelo. A revisão da literatura e o mapeamento sistemático desenvolvidos na dissertação de mestrado tiveram contribuição significativa para a definição dos processos do modelo.

O propósito deste processo consiste em viabilizar o desempenho ambiental nas atividades relacionadas à fase de desenvolvimento do software. As ações de melhoria permitem a inserção de práticas verdes nas atividades pertencentes ao ciclo de vida do 
software. A Tabela 1 apresenta os resultados esperados para o processo e as práticasbase relacionadas.

\begin{tabular}{|c|c|c|}
\hline Resultado esperado & Práticas-base & Fonte \\
\hline $\begin{array}{l}\text { DVS1 - A documentação do } \\
\text { software é desenvolvida em meio } \\
\text { eletrônico e ferramentas para o uso } \\
\text { de rastreabilidade são estabelecidas. }\end{array}$ & $\begin{array}{l}\text { DVS.PB1: Desenvolver a documentação do } \\
\text { software em formato eletrônico. A } \\
\text { documentação do software deve ser desenvolvida } \\
\text { em formato eletrônico, facilitando o controle e } \\
\text { organização dos artefatos e a segurança das } \\
\text { informações, além disso, diminui ou evita a } \\
\text { necessidade do uso de papel no desenvolvimento } \\
\text { do software. } \\
\text { DVS.PB2: Estabelecer ferramentas que } \\
\text { permitem a rastreabilidade. Ferramentas que } \\
\text { possibilitam a rastreabilidade dos artefatos } \\
\text { gerados durante o desenvolvimento do software } \\
\text { devem ser utilizadas, pois é através da } \\
\text { rastreabilidade que é possível mensurar o } \\
\text { impacto das alterações e, por consequência, } \\
\text { medir o esforço necessário. }\end{array}$ & $\begin{array}{l}\text { (SHENOY; } \\
\text { EERATTA, } \\
\text { 2011) } \\
\text { (JOHANN et } \\
\text { al., 2011) }\end{array}$ \\
\hline $\begin{array}{l}\text { DVS2 - A vida-útil do software é } \\
\text { analisada na fase de levantamento } \\
\text { de requisitos, considerando } \\
\text { necessidades futuras e limitações } \\
\text { dos hardwares atuais. }\end{array}$ & $\begin{array}{l}\text { DVS.PB3: Analisar a vida-útil estimada para } \\
\text { o software. O software deve ser especificado e } \\
\text { desenvolvido levando em consideração as } \\
\text { características atuais e futuras dos hardwares, } \\
\text { pois é preciso evitar a necessidade de } \\
\text { substituições de hardwares com a implantação do } \\
\text { software. }\end{array}$ & $\begin{array}{l}\text { (SHENOY; } \\
\text { EERATTA, } \\
\text { 2011) } \\
\text { (JOHANN et } \\
\text { al., 2011) }\end{array}$ \\
\hline $\begin{array}{l}\text { DVS3 - Requisitos não funcionais } \\
\text { visando atender necessidades } \\
\text { ambientais são especificados. }\end{array}$ & $\begin{array}{l}\text { DVS.PB4: } \\
\text { Especificar requisitos não } \\
\text { funcionais que visam questões ambientais. } \\
\text { Requisitos não funcionais descrevendo } \\
\text { características que prezam pela qualidade } \\
\text { ambiental do software devem ser definidos. } \\
\text { Exemplos: não utilizar cores brilhantes, calcular } \\
\text { o consumo de energia estimado para o software } \\
\text { em uso ou não, etc. }\end{array}$ & $\begin{array}{l}\text { (SHENOY; } \\
\text { EERATTA, } \\
\text { 2011) } \\
\text { (JOHANN et } \\
\text { al., 2011) }\end{array}$ \\
\hline $\begin{array}{l}\text { DVS4 - Os protótipos elaborados na } \\
\text { fase de levantamento de requisitos } \\
\text { são reutilizados na implementação } \\
\text { do software. }\end{array}$ & $\begin{array}{l}\text { DVS.PB5: Reutilizar o protótipo desenvolvido } \\
\text { na fase de requisitos na implementação do } \\
\text { software. O protótipo deve ser reutilizado na } \\
\text { implementação do software, com isso, a energia, } \\
\text { o tempo e o esforço gastos na fase de requisitos } \\
\text { são reaproveitados. }\end{array}$ & $\begin{array}{l}\text { (SHENOY; } \\
\text { EERATTA; } \\
2011)\end{array}$ \\
\hline $\begin{array}{l}\text { DVS5 - Práticas de modularização } \\
\text { são empregadas no projeto do } \\
\text { software, quando necessário. }\end{array}$ & $\begin{array}{l}\text { DVS.PB6: Utilizar práticas de modularização } \\
\text { no projeto do software. A modularização } \\
\text { simplifica o projeto do software e pode tornar a } \\
\text { implementação menos complexa e, por } \\
\text { consequência, será preciso menos tempo para } \\
\text { realizá-la. }\end{array}$ & $\begin{array}{l}\text { (SHENOY; } \\
\text { EERATTA; } \\
\text { 2011) }\end{array}$ \\
\hline $\begin{array}{l}\text { DVS6 - Os componentes e métodos } \\
\text { do software são projetados visando } \\
\text { o reaproveitamento. }\end{array}$ & $\begin{array}{l}\text { DVS.PB7: Projetar componentes e métodos } \\
\text { permitindo o reaproveitamento. O } \\
\text { reaproveitamento de componentes e métodos tem } \\
\text { uma série de benefícios, mas um deles é a } \\
\text { economia de esforço e energia. }\end{array}$ & $\begin{array}{l}\text { (SHENOY; } \\
\text { EERATTA; } \\
\text { 2011) }\end{array}$ \\
\hline $\begin{array}{l}\text { DVS7 } \\
\text { - Ferramentas de automação } \\
\text { são utilizadas na fase de } \\
\text { implementação do software. }\end{array}$ & $\begin{array}{l}\text { DVS.PB8: Utilizar ferramentas de automação } \\
\text { na implementação do software. Ferramentas } \\
\text { para geração e análise automática de código e } \\
\text { para análise permitem a redução do tempo } \\
\text { necessário para executar a tarefa manualmente e } \\
\text { a padronização do código-fonte. }\end{array}$ & $\begin{array}{l}\text { (SHENOY; } \\
\text { EERATTA, } \\
\text { 2011) }\end{array}$ \\
\hline DVS8 - $\quad$ Testes unitários $\quad$ são & DVS.PB9: Realizar testes unitários. Os testes & (SHENOY; \\
\hline
\end{tabular}




\begin{tabular}{|c|c|c|}
\hline $\begin{array}{l}\text { realizados no final de } \\
\text { implementação. }\end{array}$ & $\begin{array}{l}\text { unitários podem minimizar a detecção de erros } \\
\text { em etapas posteriores a implementação e, } \\
\text { portanto, desempenham um papel muito } \\
\text { importante na consolidação de um software sem } \\
\text { defeitos. Quanto menos defeitos, menor a } \\
\text { necessidade de alteração e retrabalho. }\end{array}$ & $\begin{array}{l}\text { EERATTA, } \\
\text { 2011) }\end{array}$ \\
\hline $\begin{array}{l}\text { DVS9 - Testes automatizados são } \\
\text { planejados e realizados com a } \\
\text { frequência } \\
\text { planejamento. }\end{array}$ & $\begin{array}{l}\text { DVS.PB10: Planejar testes automatizados. Os } \\
\text { testes automatizados reduzem a necessidade de } \\
\text { pessoas em testes manuais. Além disso, } \\
\text { permitem a reaplicação de casos de teste e a } \\
\text { padronização do processo de testes. É necessário } \\
\text { planejar as atividades, recursos e esforços que } \\
\text { serão utilizados nesses testes. }\end{array}$ & $\begin{array}{l}\text { (SHENOY; } \\
\text { EERATTA, } \\
2011)\end{array}$ \\
\hline $\begin{array}{l}\text { DVS10 - Testes de desempenho são } \\
\text { planejados e realizados conforme } \\
\text { planejamento. }\end{array}$ & $\begin{array}{l}\text { DVS.PB11: Planejar testes de desempenho. Os } \\
\text { testes desempenho permitem identificar } \\
\text { problemas de compatibilidade entre software e } \\
\text { hardwares, sendo assim o software pode não } \\
\text { funcionar corretamente com sistemas atuais ou } \\
\text { legados que apresentarem menor capacidade. É } \\
\text { necessário planejar as atividades, recursos e } \\
\text { esforços que serão utilizados nesses testes. }\end{array}$ & $\begin{array}{l}\text { (SHENOY; } \\
\text { EERATTA, } \\
\text { 2011) }\end{array}$ \\
\hline
\end{tabular}

Tabela 1. Resultados esperados x Práticas-base do processo DVS.

As práticas-base representam, segundo a ISO 15504 (ABNT, 2008), atividades que, quando executadas de forma consistente, contribuem para o alcance do propósito do processo. Dessa forma, para cada resultado esperado para o processo, são definidas uma ou mais práticas-base que auxiliam o entendimento e a implementação do resultado.

Todos os resultados esperados do processo possuem relação com práticas ambientais, conforme apresentado na coluna Práticas-base da Tabela 1. No entanto, é possível constatar que estes resultados esperados também prezam pela qualidade do software. Por isto, esta pesquisa conclui que ações ambientais empregadas no processo de desenvolvimento de software também contribuem para a qualidade dos softwares desenvolvidos, permitindo que a organização melhore seus processos de desenvolvimento visando à qualidade ambiental e, ao mesmo tempo, do software. Dessa forma, entende-se que a qualidade ambiental não exclui a qualidade do software e sim complementa os processos da empresa.

$\mathrm{Na}$ implementação do modelo em organizações de software, este processo é obrigatório e também deve ser avaliado em relação aos atributos de processo definidos em cada nível de capacidade.

\subsection{Níveis de capacidade}

Para a dimensão de capacidade dos processos do modelo MPVerde foram definidos quatro níveis. No total, foram definidos onze atributos de processo (PA) relacionados à dimensão de capacidade de cada nível de maturidade do modelo (V1, V2 e V3). A análise das normas ISO 15504-5 e ISO 14001 contribuiu significativamente para o desenvolvimento destes atributos de processo. É possível perceber que a maioria está relacionada a necessidades da gestão ambiental, especificadas na ISO 14001. O nível 0 
de capacidade é definido como o nível inicial e não possui práticas associadas, ele representa que o processo não é implementado ou que possui falhas em alcançar o resultado esperado.

O nível 1 de capacidade representa que o processo é gerenciado e, para isso, é preciso demonstrar os atributos de processo: PA1 - O processo atinge seus resultados definidos, PA2 - A documentação formal do processo é estabelecida, mantida e comunicada a todos os envolvidos, PA3 - O processo é planejado e monitorado, PA4 Os papéis e responsabilidades requeridos para executar o processo são identificados, PA5 - As pessoas que executam o processo são capacitadas e PA6 - O processo está especificado na política ambiental da organização.

O nível 2 é definido que o processo é institucionalizado. São avaliados os atributos de processo: PA7 - Um grupo de colaboradores é formado para discutir e revisar o processo e PA8 - Os resultados do processo são revistos com diferentes níveis hierárquicos da organização, incluindo a alta direção para fornecer visibilidade.

E, finalmente, o nível 3 representa que o processo é medido e avaliado continuamente. Para avaliar este nível são demonstrados os atributos de processo: PA9 Resultados obtidos com a execução do processo demonstram benefícios ambientais, PA10 - Medidas do processo são coletadas e analisadas para apoiar a tomada de decisão sobre soluções ambientais e PA11 - Oportunidades de melhoria derivadas de inovações tecnológicas e soluções ambientais são identificadas, avaliadas e selecionadas para apoiar o alcance dos objetivos de negócio.

Os atributos de processo PA2, PA4, PA6, PA8 e PA10 foram identificados especificamente a partir da análise dos requisitos exigidos pela norma ISO 14001. Com o atendimento destes atributos é possível garantir a existência da política ambiental e formalização dos processos nesta política, definindo os papéis e responsabilidades envolvidos, a análise da administração na tomada de decisões, assim como medições para identificação de ações corretivas e preventivas.

\section{Avaliação do MPVerde}

Para avaliação do modelo, foram realizadas entrevistas em três empresas de software que se prontificaram a colaborar com a pesquisa. Esta entrevista teve como objetivo avaliar a viabilidade técnica e financeira para se atingir o resultado esperado de cada processo, assim como a relevância que o entrevistado atribui ao resultado esperado. Nesta oportunidade, também foi possível identificar se a empresa já executa o resultado esperado e, com isso, foram coletadas as evidências de execução. A Figura 3 apresenta o formato da avaliação:

\begin{tabular}{l|c|c|c|c|c}
\hline $\begin{array}{l}\text { Processo: } \\
\text { Gerência do Lixo Eletrônico }\end{array}$ & $\begin{array}{c}\text { Viabilidade } \\
\text { técnica }\end{array}$ & $\begin{array}{l}\text { Viabilidade } \\
\text { financeira }\end{array}$ & Relevância & Atendimento & Evidências \\
\hline $\begin{array}{l}\text { GLE1 - Critérios de classificação } \\
\text { dosmateriais são definidos. }\end{array}$ & $<1.3\rangle$ & $\langle 1.3\rangle$ & $<0.5\rangle$ & $\langle$ N,P,L ou T $>$ & $<$ Texto $>$ \\
\hline
\end{tabular}

Figura 3. Formato da avaliação de cada resultado esperado. 
$\mathrm{Na}$ avaliação da viabilidade técnica e financeira, os itens foram pontuados de 1 a 3, onde 1 a implementação é inviável e 3 é viável. Em relação à relevância, os itens foram pontuados de 0 a 5 , onde 0 o item se caracteriza como irrelevante e 5 como muito relevante. $\mathrm{O}$ atendimento do resultado esperado foi pontuado como ' $\mathrm{N}$ ' não atende, ' $\mathrm{P}$ ' atende parcialmente, ' $\mathrm{L}$ ' atende largamente ou ' $\mathrm{T}$ ' atende totalmente. As evidências foram coletadas em forma textual.

Dois perfis de entrevistados foram necessários nesta avaliação. $O$ perfil administrativo precisava possuir envolvimento nas iniciativas ambientais realizadas na organização e ter conhecimento sobre as diretrizes de recursos humanos quanto à capacitação de profissionais. O perfil técnico refere-se a um profissional de TI com conhecimento sobre as políticas e diretrizes da organização relacionadas a desenvolvimento de softwares e infraestrutura necessária, ter noção de programação, soluções e ferramentas utilizadas para desenvolvimento. No total foram entrevistadas oito pessoas. Cada entrevista teve em média duração de duas horas.

As iniciativas ambientais já implementadas pela empresa foram coletadas como evidência de execução de alguns resultados esperados. Através desta avaliação, foi possível classificar as empresas entrevistadas em relação aos níveis de maturidade e capacidade do modelo. Esta classificação demonstrou o nível de conscientização e investimentos da empresa em relação a questões ambientais.

\subsection{Caracterização das empresas avaliadas}

As três empresas entrevistadas são de Santa Catarina e têm como principal ramo de atividade o desenvolvimento de software. Estão sediadas em Florianópolis, mas possuem filiais em outras cidades.

A Empresa 1 atua no mercado de software há mais de 20 anos e seus clientes principais são órgãos públicos e universidades. Seus softwares são comercializados como produtos com foco, principalmente, em soluções administrativas para a gestão pública e o judiciário. Possui cerca de 600 funcionários na sede em Florianópolis e cerca de 300 funcionários nas demais filiais.

A Empresa 2 foi fundada em 1977 também em Florianópolis. Desenvolve soluções em Inteligência, TI e Telecom para empresas de segmentos corporativos, órgãos públicos, hospitais e universidades. Atualmente, possui cerca de 700 funcionários na sede e filiais.

A Empresa 3, também de Florianópolis, está há 10 anos no mercado de TI e possui produtos que podem ser comercializados para qualquer mercado, ou seja, seus produtos são multimercados. Possui duas principais soluções que tratam de digitalizações de documentos e coleta de informações de domínio público para gestão e comércio. Possui cerca de 200 funcionários na sede e filiais.

\subsection{Resultados da avaliação}


A avaliação realizada nesta pesquisa teve como objetivo principal analisar a viabilidade técnica e financeira de implementação do modelo. Nesta oportunidade de apresentação do MPVerde para gerentes e coordenadores destas empresas foi possível também avaliar a opinião deles em relação a relevância de cada processo proposto no modelo. A Tabela 2 apresenta os resultados obtidos com a avaliação da viabilidade e relevância dos processos nas empresas.

\begin{tabular}{|c|c|c|c|c|}
\hline Processo & & Empresa 1 & Empresa 2 & Empresa 3 \\
\hline \multirow[t]{3}{*}{ Gerência da Solução Verde } & Viabilidade técnica & 3 & 3 & 3 \\
\hline & Viabilidade financeira & 3 & 3 & 2 \\
\hline & Relevância & 4 & 5 & 5 \\
\hline \multirow{3}{*}{$\begin{array}{l}\text { Gerência do Centro de } \\
\text { Processamento de Dados }\end{array}$} & Viabilidade técnica & 3 & 3 & 3 \\
\hline & Viabilidade financeira & 3 & 2 & 1 \\
\hline & Relevância & 5 & 4 & 4 \\
\hline \multirow[t]{3}{*}{ Gerência do Lixo Eletrônico } & Viabilidade técnica & 3 & 3 & 3 \\
\hline & Viabilidade financeira & 3 & 3 & 3 \\
\hline & Relevância & 4 & 4 & 5 \\
\hline \multirow[t]{3}{*}{ Gerência de Riscos Ambientais } & Viabilidade técnica & 3 & 3 & 3 \\
\hline & Viabilidade financeira & 3 & 2 & 3 \\
\hline & Relevância & 4 & 5 & 3 \\
\hline \multirow[t]{3}{*}{ Aquisição Verde } & Viabilidade técnica & 2 & 3 & 3 \\
\hline & Viabilidade financeira & 3 & 2 & 1 \\
\hline & Relevância & 4 & 5 & 3 \\
\hline \multirow{3}{*}{$\begin{array}{l}\text { Avaliação e Melhoria da } \\
\text { Solução Verde }\end{array}$} & Viabilidade técnica & 3 & 3 & 3 \\
\hline & Viabilidade financeira & 3 & 3 & 3 \\
\hline & Relevância & 5 & 3 & 3 \\
\hline \multirow{3}{*}{$\begin{array}{l}\text { Desenvolvimento Verde de } \\
\text { Software }\end{array}$} & Viabilidade técnica & 3 & 3 & 3 \\
\hline & Viabilidade financeira & 3 & 3 & 3 \\
\hline & Relevância & 5 & 5 & 4 \\
\hline \multirow{3}{*}{$\begin{array}{l}\text { Implantação e Desativação } \\
\text { Verde de Software }\end{array}$} & Viabilidade técnica & 3 & 3 & 3 \\
\hline & Viabilidade financeira & 3 & 3 & 3 \\
\hline & Relevância & 5 & 5 & 5 \\
\hline \multirow[t]{3}{*}{ Medição da Solução Verde } & Viabilidade técnica & 2 & 3 & 3 \\
\hline & Viabilidade financeira & 2 & 3 & 3 \\
\hline & Relevância & 4 & 5 & 5 \\
\hline \multirow{3}{*}{$\begin{array}{l}\text { Treinamento para Soluções } \\
\text { Verdes }\end{array}$} & Viabilidade técnica & 3 & 3 & 3 \\
\hline & Viabilidade financeira & 3 & 3 & 3 \\
\hline & Relevância & 4 & 5 & 5 \\
\hline \multirow{3}{*}{$\begin{array}{l}\text { Gestão do Conhecimento } \\
\text { Ambiental }\end{array}$} & Viabilidade técnica & 3 & 3 & 3 \\
\hline & Viabilidade financeira & 3 & 3 & 3 \\
\hline & Relevância & 4 & 5 & 5 \\
\hline
\end{tabular}

Tabela 2. Resultado da avaliação dos processos. 
Com os resultados apresentados na Tabela 2, foi constatado que há interesse por parte das três empresas em financiar projetos ambientais e, com isso, melhorar as suas atividades e processos organizacionais visando o desenvolvimento sustentável. No entanto, para que seja aplicado um maior investimento financeiro com estas ações é necessário que haja um interesse de mercado e, principalmente, por parte do governo.

Em relação à quantidade e qualidade das iniciativas ambientais empregadas, a Empresa 2 se destacou dentre as três. A Empresa 1 apresentou 12 ações ambientais, em destaque ao projeto de separação dos lixos, onde foram distribuídas lixeiras específicas para cada tipo de lixo em todos os andares do prédio, além do trabalho de conscientização dos funcionários através de comunicados internos. A Empresa 2 apresentou 22 principais ações ambientais, em destaque ao trabalho de medições e coleta de indicadores para tomadas de decisões em relação a consumo de energia, combustível, água, copos e papéis, cálculo da emissão de $\mathrm{CO}_{2}$ visando a conscientização e diminuição de viagens, e cálculo da quantidade de eletrônicos descartados e total de lixos eletrônicos produzidos. A Empresa 3 apresentou 9 ações ambientais, em destaque o projeto Carbon Free, onde anualmente a empresa realiza o cálculo das emissões de $\mathrm{CO}_{2}$ e repassa o valor necessário para uma $\mathrm{ONG}$, responsável por plantar árvores com o objetivo de neutralizar o dióxido de carbono emitido.

Em relação às iniciativas ambientais empregas no desenvolvimento de software se destacam: documentação em formato eletrônico e rastreada nas três empresas; testes unitários e testes automatizados de interface opcionais nas Empresas 2 e 3, e obrigatórios na Empresa 1; práticas de modularização e reaproveitamento de códigosfonte empregadas nas três empresas; preocupações para que não haja necessidade de atualização de hardware para utilização do software desenvolvido na Empresa 2; notebooks utilizados em todos os setores da Empresa 2, principalmente, na área de desenvolvimento de software, pois possuem maior durabilidade e consomem menos energia; configuração padrão e obrigatória para hibernar todos os notebooks a cada 15 minutos sem uso, aplicada na Empresa 2, auditorias são realizadas mensalmente para garantir esta configuração da máquina.

As três empresas apresentaram iniciativas ambientais com interesse direto ou indireto na preservação do meio ambiente. Em conclusão aos resultados obtidos nas avaliações, ficou constatado que as ações ambientais destas empresas são empregadas de forma pontual e isoladas, o que segundo a definição do modelo, caracteriza que estas empresas não adotam uma gestão ambiental em seus processos organizacionais. Para que estas ações se tornem soluções verdes é necessário haver a gestão, planejamento, análise dos riscos associados, auditorias e medições, viabilizando a integração entre os processos e uma implementação de forma sistemática da gestão ambiental.

\section{Trabalhos Correlatos e Limitações da pesquisa}

Para identificar trabalhos relacionados ao tema da pesquisa foram realizados levantamentos na literatura identificando pesquisas correlatas por meio de um método sistemático e consistente. O mapeamento sistemático realizado teve como objetivo 
identificar modelos, guias ou frameworks que descrevessem processos ou práticas no contexto da TI verde. Também foi analisado se os trabalhos retornados possuíam processos e práticas com aplicação em organizações de desenvolvimento de software. Com estes critérios, foram selecionadas seis pesquisas no resultado do mapeamento sistemático: (DUBEY; HEFLEY, 2011), (HARMON; DAIM; RAFFO, 2010), (GONÇALVES; JÚNIOR, 2009), (SHENOY; EERATTA, 2011), (JOHANN et al., 2011) e (DONNELLAN; SHERIDAN; CURRY, 2011). Portanto, até o momento da elaboração deste trabalho, não foi encontrado um modelo de processos e práticas verdes voltado especificamente para organizações de desenvolvimento de software.

Os resultados das avaliações realizadas nesta pesquisa podem ser considerados como limitados, pois foram observados a partir uma amostra de apenas três empresas de software de Florianópolis. Isto conota a necessidade de novas avaliações do modelo em demais empresas e especialistas da área de TI verde.

Além disso, durante as entrevistas realizadas foi possível identificar que alguns dos entrevistados não tinham conhecimento amplo sobre todas as ações da organização o que sugere que pôde haver uma falha de comunicação. A falta de informação pode ter influenciado na qualidade do resultado obtido com a entrevista.

\section{Considerações Finais}

Esta pesquisa demonstrou a necessidade em se implementar ações ambientais no cenário de organizações de software, visto que a infraestrutura requerida e as atividades presentes nestas organizações tem influencia sobre o meio ambiente, principalmente, no que se refere a consumo de energia elétrica e lixo eletrônico. Foi possível identificar por parte de alguns entrevistados o desconhecimento sobre os impactos associados as suas atividades.

Foi possível ainda verificar que, na maioria dos casos, as ações empregadas por estas organizações são motivadas por interesses próprios, visto que muitas vezes não há apoio do governo. Enquanto, que em países da Europa, por exemplo, existem apoios financeiros como reduções de impostos e outras iniciativas vindas do governo para valorizar e incentivar estas empresas que buscam inibir seus impactos ao meio ambiente. As três empresas avaliadas relataram que a principal motivação para que haja investimento nesta área seria justamente a exigência por parte dos seus clientes. Considerando que os principais clientes destas empresas são órgãos públicos, então foi possível concluir que investimentos em projetos de implantação como do MPVerde serão possíveis quando houver interesse e exigência do governo em valorizar empresas de software que implementam ações ambientais nas contratações públicas.

Com as avaliações realizadas também foi possível perceber que as ações ambientais implantadas nestas empresas tiveram um retorno positivo por parte dos funcionários que, através de programas internos promovidos pela empresa, contribuem com opiniões e sugestões de melhorias. Isto se deve ao fato de que as pessoas estão cada vez mais conscientes e, se motivadas, podem ser estimuladas a realizar ações 
individuais em seu ambiente de trabalho e familiar. Através de relatos observados nas entrevistas, após a implantação das medidas ambientais, grande parte dos funcionários apresentou interesse em apoiar os projetos e acredita-se que um dos benefícios com a implantação desses programas seja a motivação em produzir trabalhos com mais qualidade.

Os principais benefícios apontados na implementação do modelo são a integração da gestão ambiental com os objetivos de negócio da organização, retornos financeiros advindos das soluções ambientais como economia de energia, promoção da imagem sustentável, processos organizacionais modificados visando à certificação ambiental da ISO 14001 e promoção da cultura organizacional e conscientização.

\subsection{Expectativas futuras}

Como perspectivas futuras para esta pesquisa espera-se o desenvolvimento desta avaliação em organizações de software de outras cidades do Brasil e, se possível, em empresas multinacionais. Com isso, será possível avaliar com mais precisão a aplicabilidade e viabilidade de implementação de um modelo voltado para questões ambientais neste mercado de software.

Avaliar a opinião do setor público em relação a esta iniciativa, sendo interessante identificar a expectativa do governo em analisar a situação de uma empresa de software em relação a soluções e impactos ambientais em contratações públicas.

Também é expectativa futura a implantação real do modelo em uma organização de software, sendo possível analisar de fato seus pontos falhos e tornar possíveis melhorias e refinamentos baseados em experiências práticas.

\section{Referências Bibliográficas}

ABNT: NBR ISO/IEC 12207: Engenharia de sistemas e software - Processos de ciclo de vida de software, 2009.

ABNT: NBR ISO 14001: Sistemas da gestão ambiental - Requisitos com orientações para uso, 2004.

ABNT: NBR ISO/IEC 15504 - Tecnologia de Informação - Avaliação de Processo, Parte 1 a Parte 5, Associação Brasileira de Normas Técnicas, 2008.

BOOCH, G.; RUMBAUGH, J.; JACOBSON, I. UML - Guia do Usuário. Editora Campus, 2006.

DONNELLAN, B; SHERIDAN, C.; CURRY, E. A Capability Maturity Framework for Sustainable Information and Communication Technology. Publicação: IEEE, 2011.

DUBEY, S.; HEFLEY, W.E. Greening ITIL: Expanding the ITIL Lifecycle for Green IT. University of Pittsburgh. Publicação: IEEE, 2011. 
GONÇALVES, M.B.; JÚNIOR, O.Z. Um Modelo de Referência para Desenvolvimento de Software Sustentável. Trabalho de conclusão de cursos, UFMS, 2009.

HARMON, R. R.; DAIM, T.; RAFFO, D. Roadmapping the future of sustainable IT. Publicação: IEEE, 2010.

IPEA, Instituto de Pesquisa Econômica Aplicada. Sustentabilidade Ambiental no Brasil: biodiversidade, economia e bem-estar humano, livro 7. Apoio: Secretaria de Assuntos Estratégicos da Presidência da República, Governo Federal. Brasília, 2010.

IEEE. Standard Glossary of Software Engineering Terminology. Publicação: IEEE, 1990.

JOHANN, et al. Sustainable Development, Sustainable Software, and Sustainable Software Engineering. Publicação: IEEE, 2011.

LAVILLE, E. A Empresa Verde. Editora Ote, 2009.

MURUGESAN, San. Harnessing Green IT: Principles and Practices. Publicação: IEEE Computer Society, Vol. 10, p. 24-33, Janeiro/Fevereiro 2008.

PEREIRA, R. R. Sustentabilidade - Tecnologia da Informação Verde: um guia para empresas. Florianópolis - SC, Instituto Federal de Educação, Ciência e Tecnologia de Santa Catarina. 2010.

SAHIN, et al. Towards Power Reduction Through Improved Software Design. Publicação: IEEE, 2012.

SALVIANO, C. F. Uma proposta orientada a perfis de capacidade de processo para evolução da melhoria de processo de software. Tese de doutorado pela Universidade Estadual de Campinas, Faculdade de Engenharia Elétrica e de Computação. 2006.

SEI, Software Engineering Institute. CMMI for Development: Version 1.3: CMMIDEV. USA: 2010.

SHENOY, S.S; EERATTA, R. Green Software Development Model. Publicação: IEEE, 2011.

SOFTEX. MR-MPS - Melhoria de Processo do Software Brasileiro, Guia Geral: Versão 2011. Brasília: Softex, 2011.

TACHIZAWA, T.; POZO, H. Monitoramento do Passivo Socioambiental com o Suporte da Tecnologia da Informação. Revista de Gestão da Tecnologia e Sistemas da Informação, São Paulo, v. 7, 2010.

ZOUCAS, Alessandra C. Um Framework de Métodos para o Desenvolvimento de Modelos de Capacidade de Processo. Dissertação de Mestrado pela Universidade do Vale do Itajaí, 2010. 